\title{
How Pat Metheny came to Carolina in Mpumalanga, South Africa: using music in transdisciplinary water research
}

\author{
JWN TEMPELHOFF*
}

\begin{abstract}
Listening to music can help researchers to comprehend and gain insight into complex problems in transdisciplinary research. This article explains how members of a research group at North-West University in South Africa conducted research on a crisis in the urban settlement of Carolina in Mpumalanga Province when acid mine drainage (AMD) from local coal mining operations was found in the municipal water supply.

In grappling with complex issues such as the failure of communication with local stakeholders, the group resorted to using the music of Pat Metheny's music to come to a better understanding of the crisis.
\end{abstract}

Keywords: Carolina, acid mine drainage (AMD), Pat Metheny, transdisciplinarity, coal mining.

Disciplines: History, water studies, music studies, transdisciplinary methodology.

\section{Introduction: at the point of action}

There was an atmosphere of belligerence in the main road of Carolina's Silobela township when we arrived there on the morning of 18 May 2012. On a nearby ridge a group of local residents, mostly youths, had gathered and were speaking in excited voices. Some 300 metres down the road, at the entrance to Silobela, police in riot gear stood waiting, only occasionally deliberating; constantly keeping a watchful eye on the restless crowd. An old man sauntered across the street to the home of a friend waiting for him at the garden gate. Two photojournalists stood against the perimeter fence of a corner house. They surveyed the crowd with long-lensed cameras, clicking away when an interesting image presented itself in their camera viewfinders.

- Prof. Johann Tempelhoff leads the Research Niche for the Cultural Dynamics of Water (CuDyWat), School of Basic Sciences, North-West University (Vaal), Vanderbijlpark, South Africa. Email: johann.tempelhoff@nwu.ac.za. The article is based on a colloquium presentation in the School of Musicp at North-West University (Potchefstroom) on 13 June 2013. The author acknowledges the valued advice and comments of Prof. Alta van As of the University of the Witwatersrand, as well as that of Dr Liesl van der Merwe of NWU (Potch). A special word of thanks to all members of the $\mathrm{CuDyW}$ at team who were most helpful in answering questions related to our encounters with music whilst doing research fieldwork over the years. 
Suddenly the beehive of activity quietened down and a single voice sounded the first notes of a song that was clearly familiar to all. This inspired a rhythmic response from the group; they began dancing. Shuffling their way forward to the rhythm of clapping hands and stomping feet, the group had a remarkable sense of synchronisation. They were singing in the local Swazi-Ndebele vernacular. The refrain was notable for the words "eCapitalist" and "Carolina". It was clear that they were angry and wanted to vent their feelings about an injustice they had suffered by not having access to proper drinking water.

The group had barely covered 20 metres before police opened fire with teargas. The old man who had reached the other side of the street, started coughing and tried to get out of the way in the face of what appeared to be a direct confrontation between police and the protesters. The gas proved to be too much and the youths dispersed with haste, only to regroup further up the road, ready for yet another confrontational encounter with law enforcement officials.

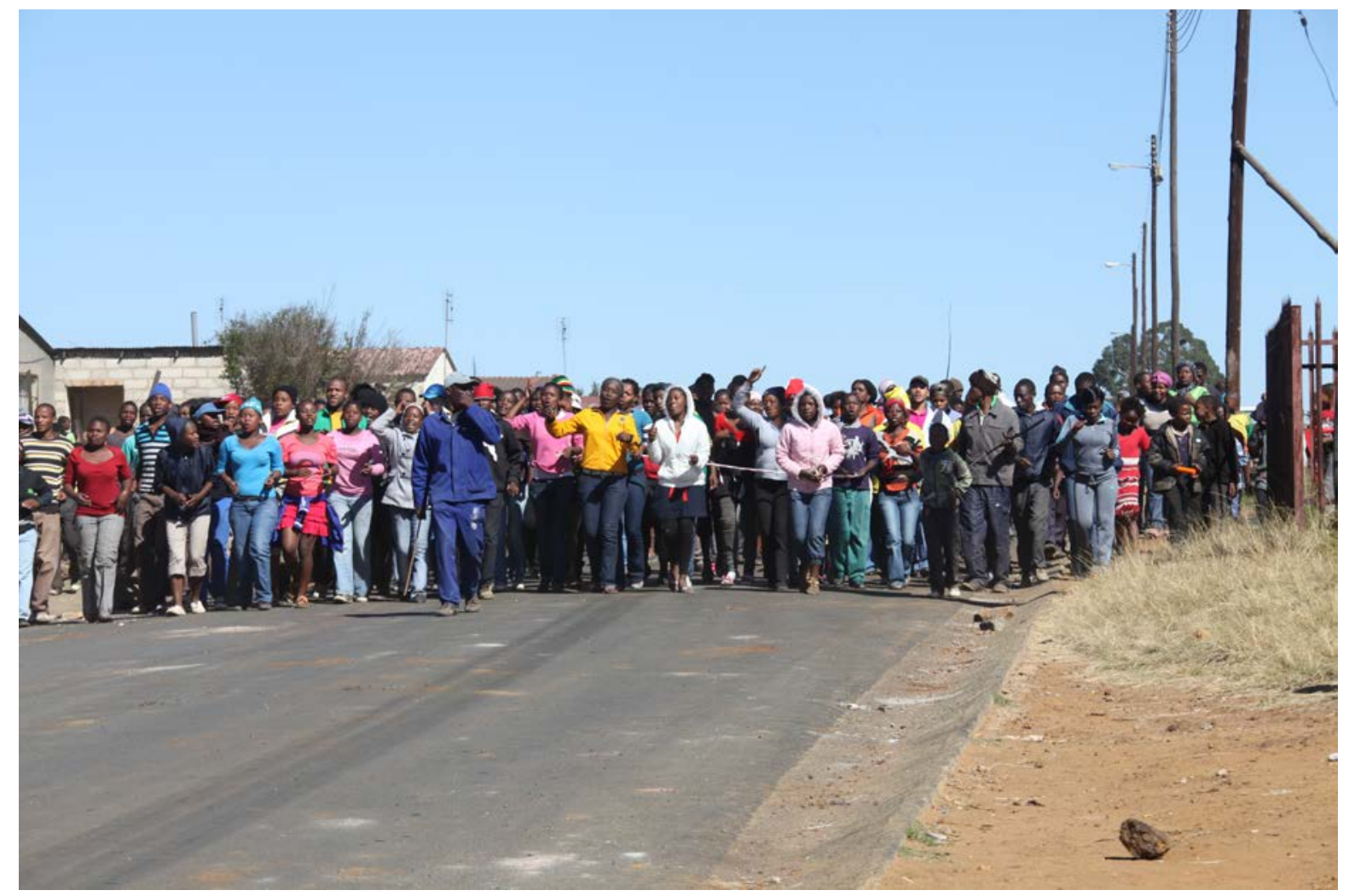

Illustration 1 On 17 May 2012, after being without a proper water supply for more than four months angry residents (mostly youths) in the Mpumalanga town of Carolina started protesting and causing considerable damage. (Photograph: JWN Tempelhoff, 18 May 2012)

Interactions of rout and rally continued until the afternoon when the protest eventually fizzled out and the youths sauntered back home to continue living out their lives with basic tap water heavily contaminated by toxic minerals in the acid mine drainage.

\section{Outline}

Against the backdrop of the brief sketch of protest in the Mpumalanga town of Carolina South Africa, the objective of this discussion is to explain how members of the Research Niche for Cultural Dynamics of Water (CuDyWat) at North-West University (Vaal) used the music of the the American jazz guitarist, Pat Metheny to come to a better understanding of a set of complex water-related problems in the South African mining town. In 2012 the group conducted research in the local municipal area when acid mine drainage (AMD) had 
contaminated the municipal water supply. The group operates within the framework of transdisciplinary research strategies and has been using music in its research projects which focus on hotspot water-related issues in municipal areas. In this discussion attention is given to the manner in which a song, performed by Pat Metheny, from his 2011 album What's it all about was used in the Carolina project and the role the music played in gaining a better understanding of the nature of the crisis experienced by the community in 2012 .

\section{Raison d'être for the Carolina project}

Members of $\mathrm{CuDuWat}$ began taking an interest in the Carolina saga in mid-February 2012. A month earlier the 17000 residents of the town woke up one morning to find that their tap water had been contaminated with acid mine drainage. We were interested in conducting what was seen as important research on acid mine drainage and its potential impact on an urban settlement. Activists have been alerting the authorities for some time to the potential high incidence of water-related conflict in the energy-development nexus sector (Munnik, Hochmann \& Hlabane, 2009; Steele \& Schulz, 2012). The need for sustainable economic growth and energy, especially coal, the major fossil fuel in South Africa, has come at a significant cost to the country, its people and an increasingly fragile biodiverse environment. In Gauteng Province, where South Africa's gold mining industry started in the 1880s, the department of water affairs, in collaboration with local authorities and a number of other stakeholders in the mining sector, have actively been collaborating since 2010 to develop mitigation strategies to reduce the potential devastating consequences of acid mine drainage in the former Witwatersrand goldfields (IMC, 2010; Prinsloo, 2010). In the Mpumalanga region of South Africa, where most of the country's coal mining has taken place since the late nineteenth century, there are now increasing indications of serious acid mine drainage problems in urban areas (McCarthy, 2011; Tempelhoff \& Winde, 2013, pp. 77-88). In the eMahlaleni District of Mpumalanga the coal mining city of Witbank has been grappling with major problems of acid mine drainage for a number of years (Sapa, 2013: McCarthy \& Pretorius, 2009, pp. 61-2). Poverty-stricken communities living on the fringes of the coal mining and electricity generation industries in Mpumalanga, are particularly vulnerable (Steele \& Schultz, 2012, pp. 7-8).

Carolina, we decided, was a worthwhile research project in that it provided us with a counterfactual micro-study of what could happen if the complex problem of acid mine drainage is not properly addressed. There is a definitive need for long-term thinking (Brand et al., 2012) on the potential negative affects of AMD in parts of South Africa. Classifying communities within this framework requires the development of 'scale free' network modelling contexts (Keller, 2005: 1060-1068; Preiser-Kapeller, 2012: 8-9) to comprehend how communities that appear to be isolated are in fact connected in time and space. The research team thus set out to determine how such communities typically respond to an extreme event such as acid mine drainage in their drinking water system.

The Carolina research was different from most other projects that we had undertaken since 2005. As a rule, our focus is on hotspot water issues. Of these local municipal potable water supply and sanitation services (Tempelhoff, et al. 2008; Gouws et al., 2009; Gouws, et al. 2010; Munnik et al., 2011), and governance-related problems (Ginster et al., 2009), were the dominant themes. In the case of Carolina we were faced with the problem of acid mine drainage contaminating the potable water supplies of an urban settlement in a predominantly 
rural region; this was described in the media as 'a modern day first' for South Africa (Tempelhoff, 2012).

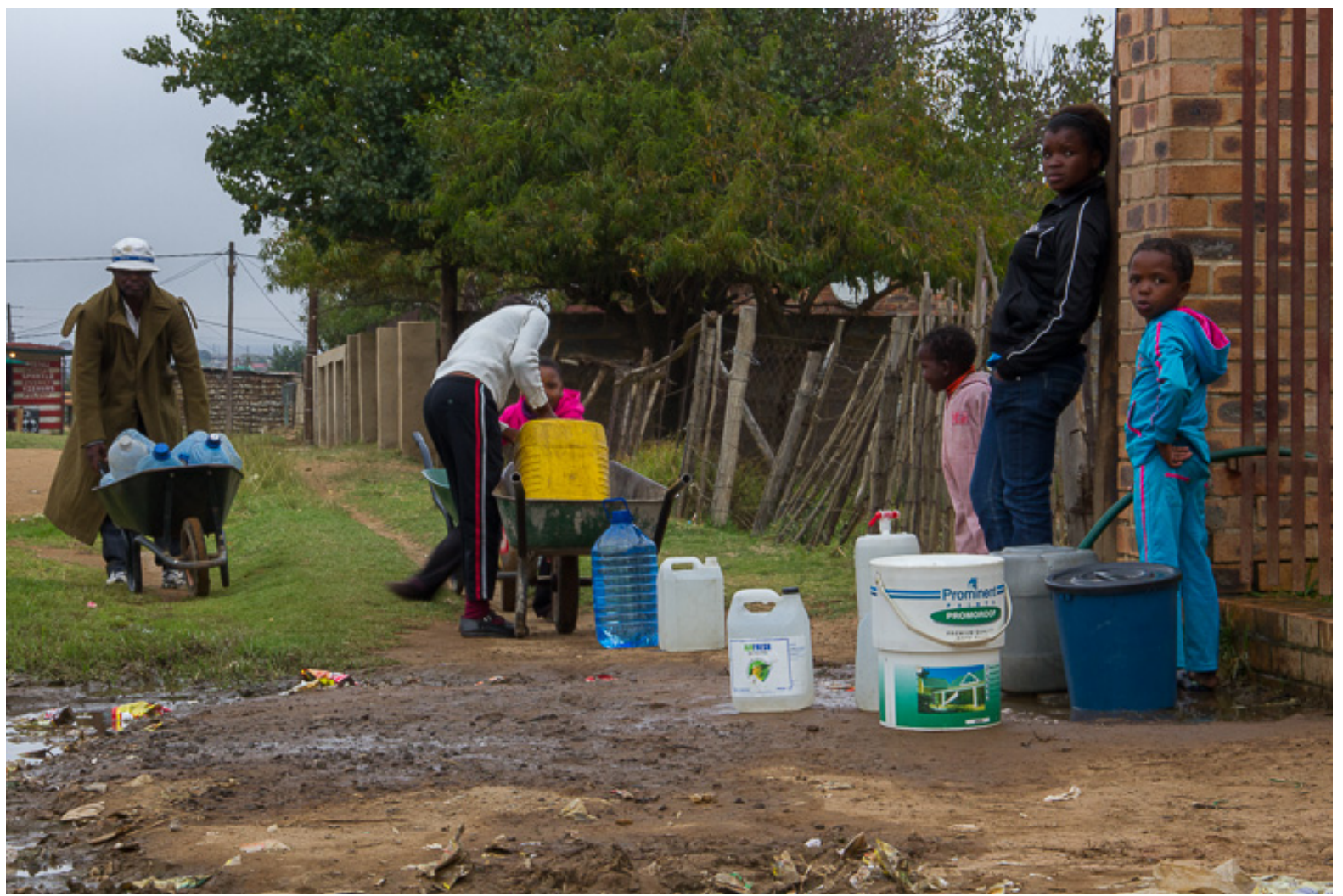

Illustration 2 Residents of Silobela collecting water from the local mosque on Friday 19 April 2012. They were still distrustful of the municipal water and told the photographer they chose not to drink municipal water. (Photograph: Franz Fuls)

Our research is based on strategies of finding ways to encourage a dialogue and cooperation between stakeholders in circumstances where there are significant water-related problems. We make a concerted effort to generate different forms of knowledge, ranging from indigenous to technical workplace-related issues, instead of imposing a single hegemonic stamp of scientific discourse in the process of finding solutions. The methodology we follow in this context is influenced by the views of Rist and Dahbou-Guebas (2006, p. 472). The practice of integration forms a key element of our research (Bergmann et al., 2012, 22-49; Pohl et al., 2008, 411-424). Therefore the participation of all stakeholders is desirable. However, officials and political leaders of the Chief Albert Luthuli Local Municipality, under which Carolina resorts, refused to collaborate with us in the research (CuDyWat, 2012). Circumstantial evidence suggests they were anxious to protect the interests of the local coal mining industry that has played an important role in the economy of Carolina since the late1970s. There was also the fact that the crisis created a politically volatile situation in Carolina. It appeared as if there were concerted attempts to draw an official security cordon around a critical condition affecting the entire community. Their uncooperative stance made it difficult for us to conduct our research in the usual manner, one we had followed for a number of years.

Fortunately, we were able to secure the collaboration of the regional office of the department of water affairs (DWA) and the management of the Incomati Catchment Management Agency (ICMA). The leadership of local civic organisations in Carolina were enthusiastic and more than willing to participate. They had experienced some frightening water-use times 
and were eager to share their insights. A manager of one of the local mining companies, allegedly partly responsible for the spill, was willing, in his official capacity, to give us an interview.

The limited participation of the authorities placed severe constraints on our research programme. Ethically, we felt compelled to seek a neutral space for conducting our research. In the group we had consensus that it would be counter-productive for us to side overtly with the activists and members of civil society who were frequently at loggerheads with the municipality and local mining companies. Consequently, selected members of our group worked with the activists (Tempelhoff, et al., 2012, pp. 54-60, 61-62), while others focused on respondents who were less articulate in their activism (Tempelhoff, et al., 2012, p. 69). We also made use of a moderator to monitor the research process. As a neutral outsider, the moderator operated on the inside in some contexts, making observations and recommendations about procedures and potential controversial issues (CuDyWat, 2012: Strauss).

By the time we visited Carolina in October 2012 to conduct the first group fieldwork, the water crisis was essentially resolved. However, there were signs of considerable public discontent and indignation about the state of affairs. People complained that the water was no longer as it used to be (Tempelhoff et al., 2012, pp. 63-84). It did not taste as good. For example, when asked what the water was like previously, people would say it tasted 'purer' and 'far better than bottled water'. It came from the clean streams on the ridges of the Incomati watershed. People remained distrustful of the local water supply and many still preferred to collect their household supplies from local artesian fountains in town or at one of the three mosques situated in various suburbs of Carolina who did not draw their water from the municipal supply (Tempelhoff et al., 2012, 45-48). In fact, our research shows that in the course of 2012 people had come to distrust the local authority. As a result of lapses in the water service, the deep-seated distrust of the water supply created a lack of confidence in the ability of the local authority to provide potable water to the residents of Carolina. The spiral of discontent that emerged from the water crisis clearly affected the fibre of the local community. The sense of place and belonging in a particular environment that they could call 'our town', or 'our place', or 'my home', had been disturbed and was in need of restoration.

\section{CuDyWat and transdisciplinary research}

Members of $\mathrm{CuDyWat}$ make wide use of transdisciplinary research. In our projects research groups typically arise when a number of interested academics agree to participate in a research initiative to investigate a complex water-related problem. The next step is to establish a participatory platform of communication with local stakeholders and then collectively start focusing on generating local knowledge, laced with academic disciplinary insights. Our ultimate goal is to find solutions to an existing problem. Transdisciplinarity does not have a specific methodology. Instead researchers rely on methodological approaches which are familiar to the participants operating in a variety of disciplines. The group then accommodates the diverse foci and strategies and to arrive at a sense of understanding of the problem at hand. It stands to reason that if and when a researcher becomes part of a research project (s)he has an intellectual contribution to make and add value which the group then absorbs. The individual's contribution (in terms of methodology) is respected and each 
participant can collaborate with a sense of belonging in the research project. We make a concerted effort to create opportunities for approaching research in an innovative manner.

In taxonomical contexts, transdisciplinarity is usually grouped with multidisciplinary (Klein, 2010, p. 17; Baumgärtner et al., 2008, p. 386) and interdisciplinary (Krohn, 2010, p. 32) research. Distinct features of transdisciplinarity include a focus on knowledge integration and a concerted effort to conduct responsible boundary work towards the absorption of relevant disciplinary foci. In the process of conducting research we work towards strong partnerships in the research group and aim to disseminate relevant scientific information in a comprehensible manner (Pohl, 2010, pp. 74-83). Transdisciplinarity is often described as the interconnection of science and society (Baumgärtner et al., 2008, p. 387). Our research aspires to seek connections with reality and real-world problems and to inform a dialectical synthesis for comprehending the dynamics of culture in a social ecological setting where there is a distinct recognition of the status of nature. For the dedicated research community, transdisciplinarity is

\section{a societal issue [which includes the] setting and the building of bridges between natural social sciences and humanities as a basis for integrating scientific as well as traditional forms of knowledge and actors (Rist \& Dahdouh-Guebas, 2006, p. 472).}

In many parts of the world transdisciplinarity has been applied to good effect in the process of establishing greater collaboration between the natural and human/social sciences (Hirsch Hadorn et al., 2008, pp. 19-39).

Transdisciplinarity features prominently in music studies (Mueller, 2002), where the approach is a platform for linking different disciplines and a variety of dimensions of thinking and acting. Sound is considered an ordinary as well as a subliminal phenomenon. Yet it is apparent that exploring the potential of acoustic perception can contribute to unusual insights (Clovjecsek, 2000, pp. 495-500). For example, at the University of Berne in Switzerland, researchers in the Institute for Transdisciplinarity have been working on Denkgeräusche, exploring the sonification of sound - or the history of sound and specifically the manner in which sounds have been incorporated into the artistic production of music. Part of their focus has been to take note of the manner in which scientists in the fields of medicine and natural science, as well as the humanities, have been collaborating in research projects to explore new frontiers of sonification (Schoon \& Dombois, 2009). Similar work, has been done, but in a more diverse mode by Rietveld (1998, 2000, pp. 28-30; 2011, pp. 4-23) and Drever (2009, pp. 163-192; Also see Rodgers, 2011). It seems there are ever increasing perspectives emerging on the development of human culture since the latter part of the nineteenth century when Alexander Graham Bell had the first telephone conversation in 1876; Thomas Edison made the first phonograph recording (1878); and Gugliemo Marconi's wireless telegraph crossed the English Channel in 1899. As was the case with the visual sensory organs, since the development of photography in the first half of the nineteenth century (Frizot, 1998:3331; Starl, 1998:21-41), the functions of our auditory senses were suddenly (and then permanently) subjected to a new spectrum of states of sonic consciousness (Sterne, 2003). Historians have started working in the field (Coates, 2005:636-665), but it clearly still seems to be work in an exploratory phase of development (Saffran, 2012). 
For the purposes of this discussion we make use of the views on transdisciplinarity ${ }^{1}$ of Montuori, who apart from creative and futurist thinking also has a keen musical inclination. He sees transdisciplinarity as an:

- $\quad$ inquiry-based, rather than a discipline-based approach to research investigation;

- $\quad$ access route of looking at things from a meta-paradigmatic perspective that relies on disciplinary knowledge, but is not confined to its detailed intricacies;

- approach that makes space for complexity that enables the researcher to contextualise and connect; and

- activity that implies that the observer is also integrated as the observed (Montuori, 2008, p. xxvii; Volckmann, 2009, pp. 280-282).

Montuori's approach is significantly influenced by the French philosopher of complexity, Edgar Morin (Montuori, 2008: ixliv).

\section{$\mathrm{CuDy}$ Wat and the use of music in research}

Over a period of several years we in $\mathrm{CuDyWat}$ have developed a strategy of incorporating music into our research. We play music in the car while travelling to various localities to conduct our fieldwork. Sometimes we travel in a combi. At other times we would travel in two or more cars. Members of the research group are, as a rule requested to bring along some of their favourite music and then they would be asked to share their music in the car. By listening to the music the participants in the research fieldwork are indirectly preparing themselves to listen to the spoken word when they conduct interviews. The music also tends to create sounds of memory embedded in the experience of fieldwork in spaces, away from their familiar spaces of work. During trips we would change passengers in the vehicles and people often reflect on each other's tastes in music. Although the music may seem to be an aside, the sound that accompanies the experience of movement in space and time seems to have a pleasant effect. Members of the research group get to know each other better as they talk about their particular preferences in music. Often the music plays while they are discussing matters of the research project under investigation, while they travel. Subconsciously the music registers in a variety of ways. It can calm them; remind them indirectly of what was said in the group earlier; or even contribute to the aesthetic experience of time and space.

At the time of deliberations on our research projects we have music playing in the background. Much the same as frankinsence, or the sound of tranquil flowing water, music tends to create a pleasant ambience when we socialise between work sessions, or just spend time informally talking about our work. Furthermore, we make a concerted effort to listen to music as a group before we begin discussions on the focus of the particular project. Given the right type of circumstances it appears from personal observation that the right type of music can create a sense of cohesion in a group. Many participants in our research projects are musical novices, but they soon become accustomed to the use of music. At first some tend to consider it an aside to the work we are doing (CuDyWat, 2013: Strauss), or feel that our community stakeholder research participants will not understand the role of music in our 
work (CuDyWat, 2013: Fulz). Researchers who have participated in two or more of our initiatives tend to be more aware of the value of the use of music. A number of researchers think seriously about the music (CuDyWat, 2013: Gouws[a]). Some have a background of formal musical training and are the most conversant participants in discussions on the topic of music. They would share some factual information on the history of a piece of music, or on a performing artist or a specific type of instrument. More than often discussions also revolve around the effect and the sheer enjoyment of the music. It is then that the way is opened up for a deeper sense of understanding by listening. Of particular importance is the fact that the music brings the novice researcher in the field into a hermeneutic circle of understanding and interpretation from the inside of what is going on outside. The auditory reception of music that elicits a verbal response implies that the individual's conscious sense and experience of listening is transferred in the spoken language with the objective of sharing verbal pictures of what was heard. Therefore participants are often asked to take note of simple elements, such as tone, melody, harmony and rhythm and contemplate the potential sound message it conveys. The objective is to create an open and flexible auditory ecology for thinking about the research problems we are trying to comprehend and resolve. While tone, melody, rhythm, and sometimes even harmony may register in the spoken word, in the key of music there is an artistic aesthetic that is intended to appeal to the senses where the meanings of words only form part of the transmitted message. For the listener who is conscious of music the auditory message can appeal to the research participant in much the same way as a photograph or painting - an aesthetic that is functional, yet also artistic and creative.

In $\mathrm{CuDyWat}$ we use music for a number of reasons.

\section{Integrating social diversity through music}

Our researchers come from different social ecologies. Some are students living in university residences. Others come from the business and industrial environment. There are also of course the studious types who spend a great deal of their time in confined spaces reading and focusing on computer screens. Therefore, we argue that while in the field if we are holding discussions or are involved in individual reading and writing, music can act as a bonding agent between group members. By creating an ambient sound environment it is possible to also create a team-spirit. The ambient polyphony of a familiar home or study environment, the sounds of the office, the factory, city, or a student community in class or relaxing in the campus restaurant, are different from the auditory soundings available at the time of fieldwork. Music can act as a cohesive force and so maximise the valuable (but often limited) time a research team has at its disposal.

\section{Music and memory}

Music can potentially strengthen short and long term memory about the work we are engaged in. The music can also create an emotional response that is potentially conducive to research. As Levitin suggests:

When we love a piece of music, it reminds us of other music we have heard, and it activates memory traces of emotional times in our lives (Levitin, 2006, p. 192).

If it is possible to nurture or harbour potential memories of research fieldwork and discussions on a research problem under investigation through the medium of music, the approach can add value to research. In short, it is accepted that music can contribute to creating a sense of enjoyment and also encourage reflexive memory of work done by members of the research team (Grahn, 2013). 


\section{Trauma therapy}

Places we visit at times while undertaking research have the potential to traumatise researchers. Witnessing first-hand the abject poverty-stricken circumstances under which people live; the derelict condition of local water infrastructure; or the aura of squalor in informal settlements, can be extremely traumatic. Environmental degradation can also be traumatising for both researchers and participants alike. It was Glenn Albrecht, an Australian professor in the field of environmental psychology who coined the term solastalgia for an emotional state which he observed. He described it as a psychological condition that arose when people were emotionally saddened by the decline of the environment in which they live (Albrecht, 2006, pp. 34-36; Albrecht et al., 2007, pp. S95-S98; Glacking, 2012, pp. 209-218; Hoffner, 2012; Summers, et al., 2012, pp. 327-340). There is also evidence that researchers working in degraded environments where people are clearly suffering - for example as a result of the lack of clean drinking water or proper sanitation can suffer from a solastalgia. It is our conviction that music can be used as a form of therapy and potential solace when we contemplate strategies aimed at finding solutions to problems experienced in the local hydrosphere (Stein, 2004, pp. 783-811; Anguelovski, 2013, pp. 160-175).

\section{Agency role for music}

What we are in fact seeking is an agency role for music as medium of mimesis to help cultivate and nurture an understanding for a sense of reality, as an alternative medium of reality. Every research project we undertake is in a different spatial context. Therefore the latent consciousness of the researcher in recollecting what transpired is unique for every field trip. Apart from universalising the concept of space or location, it makes sense to promote auditory memorisation of music related to a specific research project. In dealing with consciousness of location, Chambers explains how music migrates (between culturally demarcated spaces) and the manner in which the journey in space translates into 'poetics that unfolds beneath the sky of a world which does not necessarily originate from our actions' (Chambers, 2012, p. 14). The history of music is filled with examples of how such transformations took place and the way in which sounds changed and influenced the cultural reception of foreign auditory effects that were integrated and absorbed in the cultural environment of a given society. In our own experience there are examples of how jazz music from the American Midwest (Metheny, 1982), proved to be a valuable vehicle for comprehending how difficult it is to synchronise the perceptions of farmers as water users with that of officials of the South African department of water affairs (Ginster et al., 2009).

The blending of poetics and music dates back to antiquity, but there is also recognition of the fact that there is difficulty in reconciling, especially instrumental music with the spoken word. Interestingly, Prieto suggests that where music is used in conjunction with, for example, the literary text there should be an inwardly directed auditory mode of 'listening in', 'where the primary object of representation is not the outside world but the subtly modulating interactions between consciousness and the world' of which we become aware through the media of text and music (Prieto, 2002, pp. x, 4-5).

In our research we try not only to work through the medium of the text, but also the exchange of ideas under empirical circumstances of speech exchanges in the dialogue emerging from interviews. Our research participants make notes and some make digital recordings of their interviews. There is thus a strong accent on the auditory faculty. Listening to music played at the time of fieldwork can potentially add a long-term auditory message of consciousness and hermeneutic understanding situated in the cognitive faculties of the 
individual researcher. Therefore music should be seen as a mimetic representation of a sense of 'real' space that harbours memories of thought formulated and spoken within a research group at the time of fieldwork. It is also a means of cultivating recollections of what transpired in the intellectual creation of knowledge in a group context.

\section{Teaching researchers to listen: working on oral histories}

For historians working in transdisciplinary water projects the methodology of recording interviews, taking notes and then resorting to the hermeneutic interpretation of what relevant thought was communicated, is a familiar methodological procedure. Oral history (Thompson, 2000; Thompson, 2007, 49-70; Yow, 1994) has been refined and has reached levels of considerable sophistication over many years by following the well-known examples set by the peoples' history and the history workshop movements (Samuel, 1981; Welchel, 2009, pp. 85-120). Much of the methodology used today is based on the work of anthropological researchers in the post-colonial era after World War 2 (1939-1945). In Africa this methodology made a valuable contribution towards the development of modern African history. In South Africa oral history research is a lively field of investigation (Moonie, 2013).

Although CuDyWat's research activities include historians, many of our specialist researchers come from other disciplines. Usually they undergo a brief training session to learn the basics of conducting oral interviews in the field. Many slot easily into the work and some even express how they enjoy the heuristic process of collecting this type of information. Over time many natural science researchers have pursued challenging oral research objectives and have developed innovative strategies for the transmission of information gleaned from fieldwork. When we are able to bring in local residents as stakeholder participants in our research work, they also undergo elementary training of how to conduct an interview. Sometimes they make their own notes and actively participate in daily de-briefing sessions while some of the research participants make notes and digital recordings of what is said. These participants usually work in the field with a specialist researcher. Thus fieldwork, especially the interviews conducted, become a collaborative project.

The transmission of information collected during interviews is usually in the form of written notes and/or digital recordings. These are then recorded in the researcher's personal archive. The ideal is for the information to be contextualised in a written discourse after the day's fieldwork, only later to be incorporated into a narrative discourse of his/her choice in the project report.

Grasping the significance of what has been said and the thoughts exchanged between researcher and respondent remain an open space to promote spontaneity in a complex communications network that evolves during a research fieldwork session. Much of what transpires in an interview is the result of a form of speech improvisation to shed light on a given reality related to a water-based problem. It is here where music acquires special value. The language, especially of instrumental music, is universal. It transcends the narrow confines of speech transmission by integrating rhythm, melody harmony and distinct tones that can create an atmosphere which resonates with basic human emotions.

\section{Meaning and the transmission of sound}

Making use of music in the research group was at first intended to provide a moment's reflection on the auditory and cognitive states of consciousness we go through in the process of conducting fieldwork. Talking to respondents from all walks of life about issues of water by 
implication means that the researcher is constantly exposed to the absorption of sound. Sound coming over in the form of speech may be profound. It can also be mundane. The transmission of sound is a set of coded messages that the researcher instinctively either discards or begins to interpret so as to extract information relevant to the research at hand. Our respondents in the field come from different language orientations. Alternatively they communicate with us in a language that is not their own. Nor would the language of communication necessarily be the researcher's first language. South Africans have developed interesting strategies of verbal communication and understanding and in most cases they are able to understand each other. When we communicate with people on water issues in the field there is usually a great deal of correspondence and mutual understanding between the researcher and the respondent. The issue of water supply or proper sanitation can be an emotional matter and there seems to be a common ground of communication in gestures and visual examples to substantiate a point that needs to be made.

\section{Music and the 'Rainbow Nation'}

The use of music is also based on the auditory or polyphonic work we are doing in the field. Much of our time is spent on conducting oral interviews with local residents who are directly affected by water-related problems. In many cases, poverty-stricken people in informal settlements are the most directly affected by lapses in proper water service delivery. It is also here that some of the most significant cultural diversity prevails.

Since the 1990s South Africa is often referred to as the Rainbow Nation (Botha, 2000, pp. 51-76). The country is a melting pot of cultural diversity, with 11 official languages and a substantial variety of unique cultural communities that tend to co-exist in a youthful democracy where social and economic development are dominant aspirations of a society that hopes to modernise and globalise. However, there are persistent indications that many communities aspire to maintain their unique cultural and ethnic traditions which are rooted in Africa, Western Europe and Asia. Since the 1990s the African cultural spectrum has become broader as a result of an influx of people, very often refugees, from neighbouring states and countries elsewhere in Africa. This phenomenon is also evident in the rural parts of the country where a great deal of our research takes place.

For the researcher, music can be an important medium for cultivating a better ear in listening to what goes on not only in terms of the polyphony of sounds, e.g. in a busy township, or a business district, but also in speech communication while conducting interviews. Unwittingly the researcher is often exposed to the aura of a unique sound performance (McRae, 2013, pp. 115-124) when a respondent in an interview explains how water is procured; displays the utensils for storing water; and even describes with gestures and utterances what problems are experienced in the water realm.

The language of the spoken word can also become a metaphor for the sound of water running from a tap, or the pitcher that is filled at a stream and even the sound of a toilet that is flushed, a hosepipe watering a garden and the splash of laundry being washed. Also in these unspoken auditary images there is evidence of rhythm, tone, melody and harmony that can be related to the idea of sounds of music of people alive to the realities of living in a culturally diverse society. 


\section{Types of music used in research}

We have used various types of music in our research process. However, it appears as if contemporary jazz and popular music, work best. We have a diversified audience of listeners and need to create a soundscape that takes participants out of their conventional listening comfort zones, but also appeals to their sense of aesthetics. In one of our research projects we asked participants to bring along at least one CD featuring their favourite music. As the day's fieldwork involved travelling, the plan was to listen to the music informally and exchange our views of the relevance of the different tracks to the research. Later we selected one of the songs - "Nine million bicycles" performed by Katie Melua (Melua, 2005). The significance of the song was that it dealt with the issue of love, in the context of the research project, for the Marico River in North West Province. This fondness appeared to be bereft of logic, but at the same time, we are told by the singer to accept it as a fact, much as we accept the astronomical fact that we are 'twelve billion light years from the edge'; the statistical reality that there are nine million bicycles in Beijing; and the demographic fact that there are now just over seven billion people on the globe (Batt, 2007). The song not only made sense to the members of the research group, but also to stakeholders some months later when we shared the findings of the report at a public meeting (Bertram et al., 2010).

\section{How Pat Metheny came to Carolina}

The use of Pat Metheny's music in the Carolina project came quite by chance. While doing the desktop research for the project, the author spent a great deal of time listening to a wide selection of jazz music. As the fieldwork session of October 2012 came closer it registered that we should be able to use the Paul Simon song "The sound of silence", 2 featured in the 2011 solo album of What's it all about by jazz guitarist, Pat Metheny (Metheny, 2011). In the research group we grappled with the problem of getting local political leaders and officials of the Chief Albert Luthuli Local Municipality (CALM) to participate in the project. There were many political issues that seemed to militate against greater access for the public into the workings of what was going on behind the scenes of one of the major municipal water crises of 2012 in Mpumalanga. Another factor that made the song relevant, especially for members of the local community participants was the Protection of Information Bill that had been under discussion in the South African legislative assembly public since 2010. Since 2011 $\mathrm{CuDyWat}$ researchers frequently experienced problems with local authorities to give their unstinting support in our research. This being so, it became increasingly difficult to share our research findings with stakeholders. Pat Metheny's rendition of the "The sound of silence" seemed to resonate with all these underlying issues we experienced at the time.

2. A version of the song is available on YouTube at Pat Metheny, The sound of silence at http://www.youtube.com/watch?v=ieMInAkKxhY\&list=PLoHoqw2okQIpOF_3h1erKG-

CbXHQhul0J (Accessed 2013.12.19). 


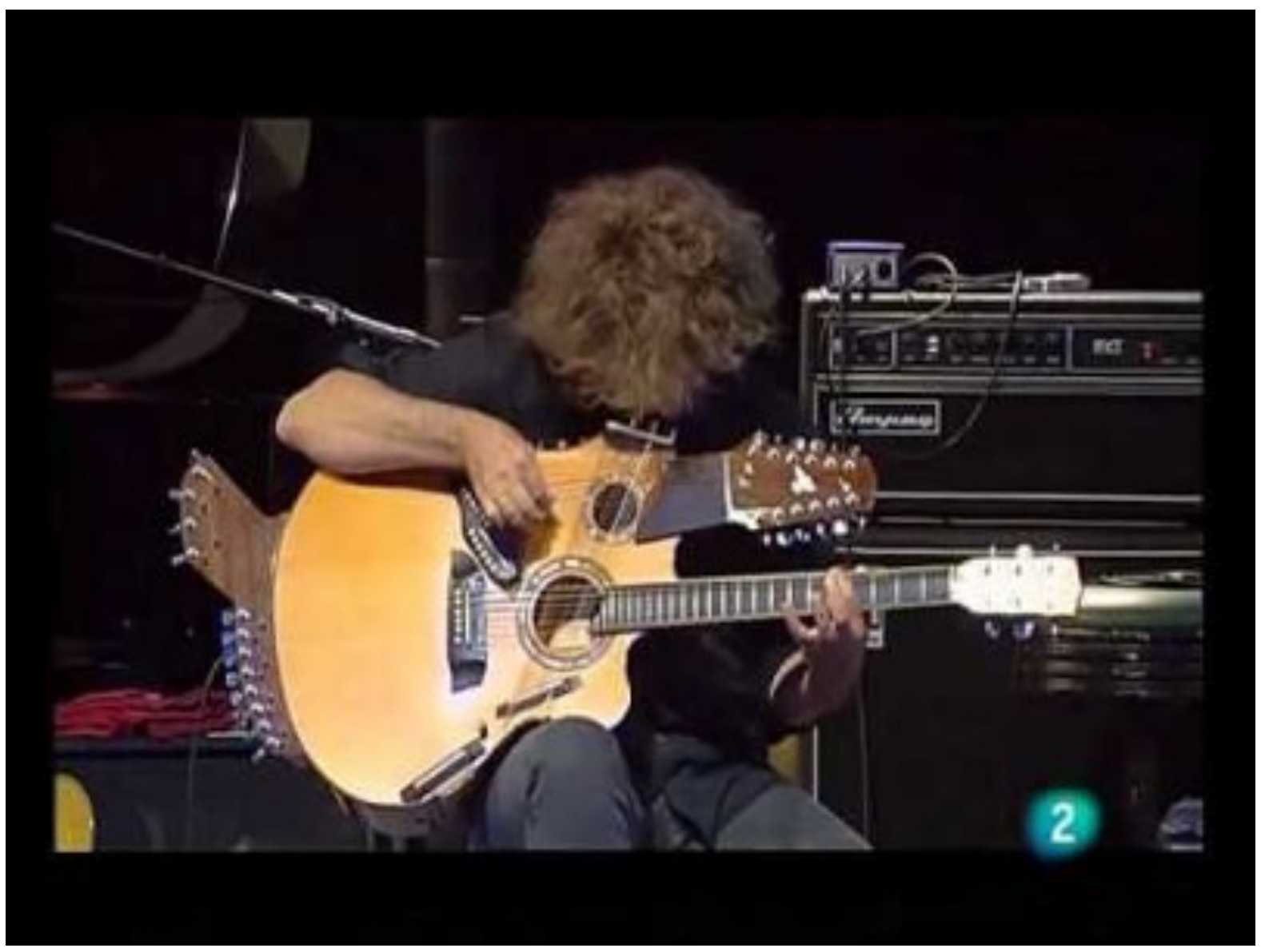

Illustration 3 Metheny playing the Pikasso guitar manufactured by Canadian lutier Linda Manzer (Photograph: Pankin, 2011)

The song has significant depth of meaning on many levels. Simon composed the song after the assassination of JF Kennedy, president of the United States of America in 1963. He recorded it with Art Garfunkel in 1964 (Simon \& Garfunkel, 1964) and by 1965 the song had become a major hit (Brackett, 2013). In 1967 "The sound of silence" featured in The Graduate, a film starring Dustin Hoffman, that acquired cult status amongst American college students (Elliot, 2010, p. 91; Monaco, 2010, pp. 179-180). The music of Simon and Garfunkel, similar to that of The Beatles, had a profound impact on a whole generation of 1960s Baby Boomers. The music formed part of protests and resistance, including anti-war sentiment; these young people were the 'movers and shakers', a generation that was distrustful of 'the establishment'. The first artists to perform the music, Simon and Garfunkel, described the meaning of the song in diverse ways. On occasion, Garfunkel explained that the song was all about the 'inability of people to communicate' and people generally being 'unable to love each other' (Elliot, 2010, p. 40; Benninghof, 2007, pp. 9-11). Simon, in turn, complained that in his early career his songs did not seem to sell well at a music publishing company he was working for. Disgruntled, he resigned and told them that he would not give them his latest composition - instead he published it himself (Anon., 2013). "The sound of silence" appears to have been a statement on the sense of alienation the composer experienced.

The effect that "The sound of silence" had on the research undertaken by the CuDyWat research team between August 2012 and March 2013 was diverse. While the fieldwork was in progress, the song immediately resonated with the mature participants. During briefing and 
discussions sessions "The sound of silence" was tellingly and metaphorically even associated with Simon and Garfunkel's album Bridge over troubled water (1970). One participant argued that that the title track, "Bridge over troubles water" would have been a more appropriate choice as theme for the Carolina project, because the research group had to breech the divide that the water crisis of acid mine drainage in the Boesmanspruit had caused between civil society in Carolina and the local authority (CuDyWat, 2012). However, we persisted with "The sound of silence" in view of the fact that we had to capture the attention and interest of a larger (and more youthful) community, most of whom had probably never heard of Simon and Garfunkel. Moreover, we needed an instrumental song which could transcend language and cultural barriers among people who had been traumatised by polluted municipal water. Metheny's music seemed appropriate for the purpose. His style of music forms part of a genre of the jazz idiom that contrasts with the conventional urban jazz environment. Metheny, as is also the case with the pianist Keith Jarrett, seems to embrace a rural, almost pastoral aura in jazz music. Ake suggests that this approach forms part of an American tradition going back to the eighteenth century; it has clear traces of the idealisation of rural and wilderness spaces. At least in the 1980s and 1990s Metheny's plaintive music-making was associated with attempts at mythologizing or imaging an ideal type of America (Ake, 2007:29-59).

Metheny's rendition of "The sound of silence" unfolds in a number of unusual contexts. The music is performed on a 42-string Pikasso guitar that produces sounds, according to critics, that confound the listening experience with apparent ease by 'coaxing a variety of tones and textures'. For most listeners, this could come across as 'impossibly unwieldy' (Kelman, 2011), and yet Metheny is able to create the sound effects of 'dreamy cascades and flourishes' (Spicer, 2011). As a rule, jazz musicians deconstruct conventional musical melodies, harmonies and rhythms with the objective of creating an improvised understanding of what the piece of music is all about at a very specific point in time - a common feature also of classical music until the end of the eighteenth century (Montuori, 2003, p. 247). In his rendition of "The sound of silence" Metheny, the leading jazz guitarist of his generation, confounded his audience in another way. The influential industry magazine Billboard in its review of the album commented on Metheny's dutiful and respectful treatment of the 'melodic and rhythmic structure' of the piece (Anon., 2011). For Bill Milkowski the guitarist makes a personal statement in his music that goes against the normal commercial instincts. Metheny's 'grab' back to the 1960s is seen as a 'visionary and grandiose sweep'. He produces a rendition of "The sound of silence" that comes over as the Zen-like use of space for a 'stirring interpretation' (Milkowski, 2012).

If it were possible to seek a sense of metaphysics between Metheny's performance and the AMD crisis in Carolina the motivation of the guitarist for recording the album seems to hold the key. What's it all about, was inspired by the 9/11 tragedy in New York City a decade earlier. It did make an impression. Metheny is an accomplished musician and this album secured for him his 19th Grammy in a career notable for creative and innovative musical artistry (Anon., 2012). The album was Metheny's second solo guitar initiative (Metheny, 2003). What stood out was that for the first time in his long recording career of more than 30 years, the album did not feature any of his own compositions (Fordham, 2011).

Our interpretation of "The sound of silence" in the $\mathrm{CuDyWat}$ research group became a multi-layered musical discourse. Originally the song had a bearing on the fact that the authorities would not speak to us. However, as we delved deeper into the realities of what had happened there was more acceptance of what had caused the disaster in the first place. Originally, we concentrated on human actors interacting with the natural environment under 
circumstances of disaster in which the water supply of a community was compromised. Human interaction with the hydrosphere implies that a cultural dynamic comes into play. A key element - water - forms part of the natural ecology of the setting in which we operate. Working in the context of social ecological systems, we used Gunderson and Holling's theory of panarchy to comprehend the infinite cycle of accumulation; collapse and alternative revival; conservation; and repeated collapse over time. This provided insight into the cyclical nature of environmental crises and helped participants to comprehend what had happened over an extended period of time (Holling, 2001, pp. 390-405; Gunderson \& Holling, 2002).

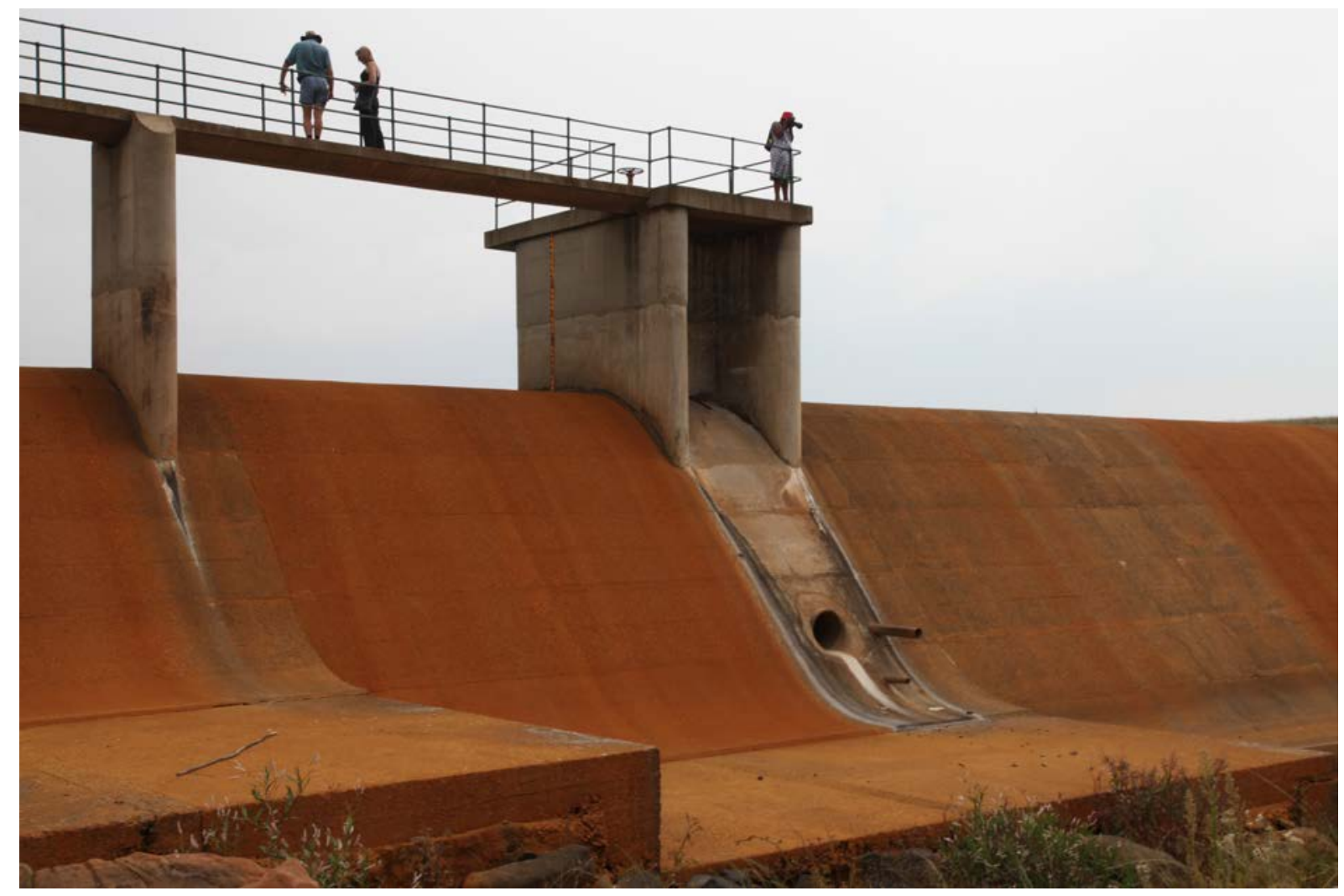

Illustration 4. The AMD-tainted weir of the municipal water storage dam of the cloal mining town Carolina in the Boesmanspruit in February 2012. What had been a reliable semi-perennial stream for many years, was not running at the time. (Photograph: JWN Tempelhoff)

Moreover, we took cognisance of posthuman reality. We pointed out that in focusing on the water infrastructure of a human community it is essential to note that technology is aimed at manipulating the local natural aquatic ecology. In other words the ecology had been disrupted by human actors, operating in a different yet integrated network. This being so, we discussed Latour's actor network theory (ANT) and worked towards identifying non-human actors in the social ecology of Carolina (Latour, 2005). By interpreting the everyday reality of the world in which we operated, the Boesmanspruit (the local stream - a tributary of the Incomati River) was in fact the prime actor in the drama that unfolded in Carolina in 2012. Indeed, in the idiom of Metheny's music, the stream supplying water to the town of Carolina spoke in silence to the social ecological system, warning the community of its imminent 'death' as a result of an over-supply of acid mine drainage. The Boesmanspruit became such a dominant voice in the drama that it affected the water supply network of the town. Not only was the water purification plant unable to process the water, but the town's pipeline network was affected for an extended period of time because the remnants of sticky acid mine drainage became lodged in the water pipeline in many of the town's low-lying areas. 
And so the use of Pat Metheny's music in our research process became an instrumental poem that mimed the circumstances of real-time drama for the ordinary resident in Carolina. In hundreds of families, almost in silence to the world outside their frontdoor, ordinary people experienced the hardship of not having access to proper drinking water. This mimetic role of the music performed an agency function for a form of hermeneutics that initially (but in a one-dimensional context) facilitated the interpretation of human actors and the consequences of their non-communication in the network. However, as we delved deeper into the contemporary natural history of the area, an important actor became the aquatic system. We were able to comprehend the profoundly silent but marked effect it had not only on the human network of participants, but even the non-human network of purification and sanitation works, the pumps, the pipelines, reservoirs and even the ordinary taps that people used to secure life-sustaining water.

\section{Conclusion}

In the process of researching and writing this text there were frequently communications with members of $\mathrm{CuDyWat}$ who feel strongly about the use of music in our research. In response to the author's constant questions on how and why they had reacted to the music, colleagues replied in metaphors. One drew a comparison with Vedran Smailović, the "Cellist of Sarajevo" who played the cello in the ruins of the Bosnian city in the early 1990s in remembrance of 22 people he had seen killed by an explosion while they were standing in a line to get food. One CuDyWat member explained that in Sarajevo's desperate situation, music was able to lift the human spirit above the violence and destructive forces of war. The use of music in our water research was then described as a search for a medium in which to understand human resilience under circumstances of hardship and suffering (CuDyWat, 2013: Gouws [b]). Another member of the group corresponded via email, while on a workrelated trip in Africa. On more than one occasion he affirmed the impact Metheny's "Sound of silence" had on his understanding of things. In one email he reported on an incident which occurred while he was travelling in a mini-bus on his way to a hotel in Dar es Salaam. A pedestrian ran in front of a vehicle in a busy street. He described the scene as follows:

The oncoming truck was travelling at a moderate to fast pace when the two (the pedestrian and the vehicle) connected after which she (the pedestrian) disappeared from view for what seemed a very long time until she appeared again in the window holding the screaming pain coming from her head. The fact that she was on her stuttering feet made me think she would be ok but I am not sure as we were waved on by the uniformed policeman ... I heard nothing. I felt everything ... That was the loudest silence I have ever heard (CuDyWat, 2013: Ginster).

Most of what we experience comes across in images and sounds. However, somehow we seldom allow the counterpoint of polyphonic sounds to register properly in all our faculties. Music, it seems, can be used as a form of mimesis for creating aural spaces in which we can recreate, re-interpret and re-search for a sense of reality that is multi-layered and deep, waiting to be interpreted by us mortal beings who, all too often, are deaf to the sound of silence. 


\section{Bibliography}

Ake, D. (2007). The emergence of the rural American ideal in jazz: Keith Jarrett and Pat Metheny on ECM Records. Jazz Perspectives 1(1), 29-59.

Albrecht, G. (2006). Solastalgia. Alternatives Journal, 32, 34-36.

Albrecht, G. Sartore, G.-M., Connor, L. Higginbotham, N. Freeman, S. Kelly, B. Stain, H. Tonna A., \& Pollard, G. (2007). "Solastalgia: the distress caused by environmental change" in Australian Psychiatry, 15, Supplement 1, S95-S98. Ake, D. (2007). The emergence of the rural American ideal in jazz: Keith Jarrett and Pat Metheny on ECM Records. Jazz Perspectives, 1, 29-59. Anon., (2011, June 17). Pat Metheny: What's it all about. Billboard, Retrieved from http://www.billboard.com/articles/review/1067755/pat-metheny-whats-it-all-about

Anon., (2012, Feb. 13). Pat Metheny wins his 19th Grammy Award. Nonesuch Journal. Retrieved from http://www.nonesuch.com/journal/pat-metheny-wins-his-19thgrammy-award-judith-sherman-named-producer-of-the-year-classical-2012-02-13

Anguelovski, I. (2013). New directions in urban environmental justice rebuilding community, addressing trauma, and remaking place. Journal of Planning Education and Research 33, 160-175. Batt, M. (2007). Nine million bicycles. In Lyricsty. Retrieved from http://www.lyricsty.com/katie-melua-nine-million-bicycles-lyrics.html

Anon., (undated) The sound of silence by Simon \& Garfunkel. Songfacts. Retrieved from http://www.songfacts.com/detail.php?id=796

Batt, M. (2005). Nine million bicycles. In K. Melua, Piece by Piece (Dramatica, UK).

Baumgärtner, S. Becker, C., Frank, K., Müller, B., \& Quaas, M. (2008). Relating the philosophy and practice of ecological economics: the role of concepts, models, and case studies in inter- and transdisciplinary sustainability research. Ecological Economics, 67, 384-393.

Benninghof, J. (2007). The words and music of Paul Simon (Praeger, Westport).

Bergmann, M. Jahn, T., Knobloch, Krohn, W., Pohl, C. \& Schramm, E. (2012). Methods for transdisciplinary research: a primer for practice (pp. 22-49). Frankfurt and New York: Campus Verlag.

Bertram, E. Breytenbach, K., Faul, A., Gouws, C., Hoffmann, M., Khoadi, J., Motloung, S., Liefferink, M., Pretorius, S., Sheer, B., Sturm, M., Tempelhoff, J.W.N., Van Zyl, A.S., Wacker, T., \& Weaver, S. (2010). "Re-discovering water roots: the consequences of nickel mine prospecting in the Groot Marico River region, South Africa” (CuDyWat, Report 2/2010. North-West University (Vaal), Vanderbijlpark.

Botha, W.J. (2000). The deictic foundation of ideology, with reference to the African Renaissance. R. Dirven, R. Frank and C. Ilie (Eds.), Language and ideology: Volume II: descriptive cognitive approaches (pp. 51-76). Amsterdam: John Benjamin Publishing.

Brackett, D. (2013). "Paul Simon" in Grove Music Online (Oxford: Oxford University Press. Retrieved from http://www.oxfordmusiconline.com.nwulib.nwu.ac.za/subscriber/article/grove/music/ 46624 ?q=paul+simon\&search=quick\&pos=1\&_start=1\#firsthit 
Brand, S. Kelly, K., Rose, A., \& Saffo, P., (2012). SALT summaries October 02002 November 02012: condensed ideas about long-term thinking (The Long Now Foundation, San Francisco).

Chambers, I. (2012). Location borders and beyond (Kindle Book, self published, 2012).

Coates, P.A. (2005). The strange stillness of the past: toward an environmental history of sound and noise. In Environmental History, 10(4), October, pp. 636-665.

Clovjecsek, M. (2000). Communication and sign-systems - an instruction attempt for transdisciplinary communication. In R Häberli (ed.), Transdisciplinarity: joint problem solving among science, technology and society, dialogue sessions and Idea market, Workbook 1 (Haffmans Sachbuch Verlag, n.p.,), pp. 495-500.

CuDyWat 2012, Carolina archive: Correspondence, J Tempelhoff - CALM and ICMA (May-October 2012).

CuDyWat, 2012, Carolina archive: Dormehl, L. Briefing session, 30 September.

CuDyWat, 2012, Carolina archive: Strauss, J documents.

CuDyWat 2013, Music archive: Emails, F. Fulz, 2013.05.13; C. Gouws [a], 2013.05.12; J Strauss, 2013.05.09; M. Ginster, 2013.05.28.

CuDyWat 2013, June 5. C. Gouws [b], telephonic communication 2013.06.05.

Drever, J.L. (2009). Soundwalking: aural excursions into the everyday. In J. Saunders (ed.), The Ashgate research companion to experimental music (Ashgate, Aldershot, 2009), pp. 163-192.

Elliot, M. (2010). Paul Simon: a life (John Wiley \& Sons, Hoboken: NJ.

Fordham, J. (2011, June 6). Pat Metheny: What's it all about: review. The Guardian. Retrieved from http://www.guardian.co.uk/music/2011/jun/16/pat-metheny-whatsit-all-about-review

Ginster, M., Gouws, C., Gouws, C.M., Mäki, H., Mathipa, R., Motloung, S., Nyandoro, M., \& Tempelhoff, J.W.N. (2009). The problem of irrigation from Lesotho Highlands water in the Liebenbergsvlei River catchment, Eastern Free State Province. Report 1/2009, Research Niche for the Cultural Dynamics of Water (CuDyWat). Vanderbijlpark, SA: North-West University (Vaal).

Glackin, S.N. (2012). Kind-making, objectivity, and political neutrality: the case of solastalgia" Studies in History E Philosophy of Biological E Biomedical Sciences, 43, 209218.

Gouws, C. Moeketsi, I.M., Motloung, S., Tempelhoff, J.W.N., Van Greuning, G., \& Van Zyl, A.S. (2010). SIBU and the crisis of water service delivery in Sannieshof, North West Province. In TD The Journal for Transdisciplinary Research in Southern Africa, 6, $25-56$.

Gouws, CM. Mbambo, B. Moeketsi, I., Morotolo, M., Motloung, S., \& Tempelhoff, J.W.N. (2010). "What about the votes? Water, sanitation and civil disorientation: the case of Maluti-a-Phofung local municipality Report, 1/2010, CuDyWat. Vanderbijlpark, SA: North-West University (Vaal). 
Grahn, J. (2012, April 26). "Music and the brain" at TED Talks. Retrieved from http://www.youtube.com/watch?v=fDfVsFxJXms\&list=PLsRNoUx8w3rNOVXY5nP OIfY0a8uK_3wKx

Frizot, M. (1998). 1839-1843 photographic developments. IN M. Frizot (ed.) A new bistory of photography (pp. 22-31). Könnemann, Milan.

Gunderson L.H., \& Holling, C.S. (2002). Panarcby: understanding transformations in buman and natural systems. Washington DC: Island Press.

Hirsch Hadorn, G., Biber-Klemm, S., Grossenbacher-Mansuy, W., Hoffmann-Riem, H.,Joyce, D., Pohl, C., Wiesmann, U., \& Zemp, E. (2008). The emergence of transdisciplinararity as a form of research. IN G. Hirsch Hadorn, H. HoffmannRiem, S. Biber-Klemm, W. Grossenbacher-Mansuy, D. Joy, C. Pohl, U. Wiesmann and E. Zemp (Eds,), Handbook of transdisciplinary research (pp. 19-39). Bern: Springer, tdnet.

Hoffner, E. (2012, Nov., 14). Trebbe Johnson, Lily Yeh, and Glenn Albrecht discuss solastalgia. Orion Magazine Podcast.

Holling, C.S. (2001). Understanding the complexity of economic, ecological, and social systems. Ecosystems, 4, 390-405.

Inter-ministerial committee (IMC). (2010). Report to the inter-ministerial committee on acid mine drainage: mine water management in the Witwatersrand goldfields with special emphasis on acid mine drainage. Pretoria: Department of water affairs.

Keller, E.F. (2005). Revisiting 'scale free' networks. BioEssays, 27, 1060-1068.

Kelman, J. (2011, June 7). Pat Metheny: What's it all about. All about Jazz, the Bigger Deeper Picture, Retrieved from http://www.allaboutjazz.com/php/article.php?id=39582\#.UXeEfSt5hJE

Klein, J.T. (2010). A taxonomy of interdisciplinarity. In R. Frodeman, J. Thompson Klein, C. Mitcham \& J.B. Holbrook (Eds.), The Oxford handbook of transdisciplinarity, (pp. 15-30). Oxford and New York: Oxford University Press.

Krohn, W. (2010). Interdisciplinary cases and disciplinary knowledge. In R. Frodeman, J. Thompson Klein, C. Mitcham and J.B. Holbrook (Eds.), The Oxford handbook of transdisciplinarity (pp. 31-38). Oxford and New York: Oxford University Press.

Latour, B. (2005). Reassembling the social: an introduction to actor-network theory. New York: Oxford University Press.

Levitin, D. (2006). This is your brain on music: understanding a human obsession. London: Atlantic Books London.

McCarthy, T., \& Pretorius, K. (2009). Coal mining on the Highveld and its implications for future water quality in the Vaal River system. In Water Institute of Southern Africa (WISA) and International Mine Water Association (IMWA), Proceedings 2009: International mine water conference, (pp. 56-65). SA: WISA and IMWA.

McCarthy, T.S. (2011). The impact of acid mine drainage in South Africa. South African Journal of Science, 107. Retrieved from http://dx.doi.org/10.4102/sajs.v107i5/6.712

McRae, C. (2013). From 'all of me' to 'all of you': listening for aura. Cultural Studies <-> Critical Methodologies, 13, 115-124. 
Melua, K. (2005). Piece by Piece. UK: Dramatica.

Metheny, P. (1982). Farmers trust. In Pat Metheny Group, Travels. USA: ECM.

Metheny, P. (2003). One quiet night. USA: Warner Bros.

Metheny, P. (2011). What's it all about. USA: Nonesuch Records.

Monaco, P. (2010). A bistory of the American movies: a film-by-film look at the art, craft and business of cinema. Maryland: Scarecrow Press.

Milkowski, B. (2012, Oct., 30). Pat Metheny: What's it all about. The Absolute Sound. Retrieved from http://www.theabsolutesound.com/articles/pat-metheny-whats-it-allabout/

Montuori, A. (2008). Foreword: Edgar Morin's path of complexity. In E. Morin, On complexity, (Translated by Robin Postel, Hampton Press, Cresskill: NJ), pp. i-xliv.

Montuori, A. (2003). The complexity of improvisation and the improvisation of complexity: social science and creativity. Human Relations, 56, 237-255.

Moonie, K. (2013, Feb., 1). Oral histories and archiving memories in South Africa. Archival Platform. Retrieved from http://www.archivalplatform.org/blog/entry/oral_histories/

Mueller, J.R. (2002). Music at work: a transdisciplinary model for individual and organizational renerwal. Phoenix: $\mathrm{PhD}$, University of Phoenix.

Munnik, V., Hochmann, G., \& Hlabane, M. (2009). Manuscript: "The social and environmental consequences of coal mining: South African case study" Environmental Monitoring Group [EMG], Final draft.

Munnik, V., Molose, V., Moore, B., Tempelhoff, J., Gouws, I. Motloung, S., Sibiya, Z. Van Zyl, A., Malapela, P., Buang, B., Mbambo, B., Khoadi, J., Mhlambi, L., Morotolo, M., Mazibuko, R., Mlambo, M., Moeketsi, M., Qamakwane, N., Kumalo N., \& Tsotetsi, A. (2011). The potential of civil society organisations in monitoring and improving water quality. Braamfontein: Mvula Trust.

Pankin, T. (2011) Pat Metheny launches three-month tour in support of What's it all about. In The Morton Report, 18 September. Retrieved from http://www.themortonreport.com/entertainment/music/pat-metheny-launches-threemonth-tour-in-support-of-what-its-all-about/

Pohl, C. 2010. From transdisciplinarity to transdisciplinary research. Transdisciplinary Journal of Engineering E' Science 1, 74-83.

Pohl, C., Van Kerkhoff, L., Hirsch Hadorn, G., \& Bammer, G. (2008). "Integration" in G Hirsch Hadorn, H Hoffmann-Riem, S Biber-Klemm, W Grossenbacher-Mansuy, D Joye, C Pohl, U Wiesmann and E Zemp (eds), Handbook of transdisciplinary research (pp. 411-424). Bern: Springer, tdnet.

Preiser-Kapeller, J. (2012, Feb., 27). Extreme events - some thoughts on a historical (long term) perspective. In Austrian Academy of Sciences, Research paper in the research focus: Complexities and networks in the Medieval Mediterranean and Near East (COMMED), Division of Byzantine Research, Austrian Academy of Sciences (pp. 34). Retrieved from http://academia.edu/3549881/Extreme_Events__some_thoughts_on_a_historical_long_term_perspective 
Prieto, E. (2002). Listening in: music, mind, and the modernist narrative. Lincoln: University of Nebraska Press.

Prinsloo, L. (2010, Feb., 3). Water woes: urgent decisions necessary to avoid environmental consequences. Mining Weekly, 16, 8-9.

Rietveld, H.C. (2011). Disco's revenge: House music's nomadic memory" in Dancecult: Journal of Electronic Dance Music Culture, 2, 4-23.

Rietveld, H.C. (2000). The body and soul of club culture. The UNESCO Courier, 53, 28-30.

Rietveld, H.C. (1998). This is our house: house music, cultural spaces and technologies. Aldershot: Ashgate.

Rist S. \& Dahdouh-Guebas, F. (2006). Ethnosciences: A step towards the integration of scientific and indigenous forms of knowledge in the management of natural resources for the future. Environment, Development and Sustainability, 8, 467-493.

Rodgers, S. (2011) Session 9 reflections: listening to and sounding soundscapes. In WordPress Blog. Doing research amongst technologies: multimedia, multiple methods and research practice today.

Saffran, S. (2012, May, 30). A brief history of listening. In R. Harrison, Entitled opinions: about life and literature. Stanford CA: Stanford University, ItunesU.

Samuel, R. (Ed.). (1981). History Workshop Series: people's history and socialist theory. London: Routledge \& Kegan Paul.

Schoon, A., \& Dombois, F. (2009). Sonification in music. Proceedings of the 15th In ternational Conference on Auditory Display, Copenhagen, 18 to 22 May, IICAD09-1-3.

Simon, P. (1970). Bridge over troubled water. In P. Simon \& A. Garfunkel, Bridge over troubled water (USA: Columbia).

Simon, P., \& Garfunkel, A. (1964). The sound of silence. In Wednesday morning, 3AM, USA: Columbia/Sony.

South African Press Association (Sapa), (2013, Apr. 18). DA welcomes Mpuma administration. IOL. Retrieved from http://www.iol.co.za/news/politics/dawelcomes-mpuma-administration-1.1502690

Spicer, D. (2011, June, 20). Pat Metheny: What's it all about review” in BBC Music. Retrieved from: http://www.bbc.co.uk/music/reviews/qrm5

Starl, T. (1998). A new world of pictures: the use and spread of the daguerreotype process. IN M. Frizot (ed.) A new history of photography (pp. 32-41). Könnemann, Milan.

Steele M., \& Schulz, N. (2012). Water hungry coal: burning South Africa's water to produce electricity: Greenpeace Report 2012. Johannesburg, Greenpeace.

Stein, A. (2004). Music, mourning, and consolation. Journal of the American Psychoanalytic Association, 52, 783-811.

Summers, J.K., Smith, L.M., Case, J.L., \& Lindhurst, R.A. (2012). A review of the elements of human well-being with an emphasis on the contribution of ecosystem services. Ambio, 41, 327-340. 
Tempelhoff, E. (2012, Feb., 15). Net suur water in hul pype. Beeld. Retrieved from http://www.beeld.com/Suid-Afrika/Nuus/Net-suur-water-in-hul-pype-20120215

Tempelhoff J.W.N., \& Winde, F. (2013). Acid mine drainage in South Africa: policy, economic issues" in T. Katko, P.S. Juuti and K. Schwartz (Eds.), Water services management and governance: lessons for a sustainable future (pp. 77-88). London: IWA Publishing.

Tempelhoff, J.W.N., Van Zyl A., Van Riet, G., Gouws, C., Jordaan, H., Motloung, S., Ludick, A., Van Greuning, G., Hardy, J., Venter, A., Hardy, J., \& Schlemmer, A. (2008). An investigation into the environmental health of the Vaal River in the vicinity of Parys. Report 01/2008, CuDyWat. Vanderbijlpark, SA: North-West University (Vaal).

Tempelhoff, J.W.N., Ginster, M., Motloung, S., Gouws, C.M., \& Strauss, J. (2012). When taps turn sour: the 2012 acid mine drainage crisis in the municipal water supply of Carolina, South Africa. Report 1/2012, CuDyWat. Vanderbijlpark, SA: North-West University (Vaal).

Thompson, A. (2007). Four paradigm transformations in oral history. The Oral History Review, 34, 49-70.

Thompson, P. (2000). The voice of the past: oral history. Oxford: Oxford University Press.

Volckmann, R. (2009). Creativity and transdisciplinarity: an interview with Alfonso Montuori. Integral Review, 5, 273-287.

Yow, VR. (1994). Recording oral history: a practical guide for social scientists. Thousand Oaks, Sage. 